\title{
Empathy Score among Student Residence Assistants in Iran
}

\author{
Najmeh Shahini ${ }^{\mathbf{1}, 2}$, Kambiz Akhavane Rezayat ${ }^{3}$, Fatemeh Behdani ${ }^{4}$, Seyed Reza Habibzadeh Shojaei ${ }^{5}$, Amir \\ Akhavan Rezayat ${ }^{6}$, Maliheh Dadgarmoghaddam ${ }^{7}$
}

\footnotetext{
${ }^{1}$ Resident of Psychiatry, Psychiatry and Behavioral Sciences Research Center, Faculty of Medicine, Mashhad University of Medical Sciences, Mashhad, Iran

${ }^{2}$ Student Research Committee, Mashhad University of Medical Sciences, Mashhad, Iran

${ }^{3}$ Assistant Professor, Gastroenterology and Hepatology Research Center, Mashhad University of Medical Sciences, Mashhad, Iran

${ }^{4}$ Professor of Psychiatry, Psychiatry and Behavioral Sciences Research Center, Faculty of Medicine, Mashhad University of Medical Sciences, Mashhad, Iran

${ }^{5}$ Student Research Committee, Department of Orthopedics, Faculty of Medicine, Mashhad University of Medical Sciences, Mashhad, Iran

${ }^{6}$ Medical Student, Student Research Committee, Mashhad University of Medical Sciences, Mashhad, Iran

${ }^{7}$ Assistant Professor of Community Medicine, Faculty of Medicine, School of Medicine, Mashhad University of Medical Sciences, Mashhad, Iran
}

\section{Type of article: Original}

\begin{abstract}
Introduction: Empathy, an essential component of the physician-patient relationship, may be linked to positive patient outcomes. This study aimed to determine the empathy score among student residence assistants (RAs).

Methods: In this descriptive design (cross-sectional study), 102 Iranian RAs participated in the study during 2015, completing the Jefferson Scale of Empathy (JSPE). Data collection was analyzed using SPSS version 17. MANOVA, independent-samples t-test, Spearman correlation and confirmatory factor analysis (CFA) were used for data analysis.

Results: Mean score of JSE in the sample was $87.06( \pm 15.14)$. The mean scores for perspective taking, compassionate care, and standing in the patients shoes were $38.90( \pm 13.11), 39.27( \pm 7.94)$, and $8.89( \pm 2.80)$ respectively. Among the three specialties, (psychiatric, internal medicine, surgery) results showed significant differences in total empathy score $(\mathrm{p}=0.001)$ and perspective taking score $(\mathrm{p}=0.008)$.

Conclusions: this study showed significant differences in total empathy score and perspective taking in three specialties. We suggest that the curriculum in Iranian RAs include more teaching on empathy and communicational skills.

Keywords: Empathy, Physician, Psychometrics, Iran
\end{abstract}

\section{Introduction}

Empathy is one of the most important aspects in the medical profession (1-10) and when it is employed in the right capacity it can be very effective in the relationship between doctor and patient (11). Empathy is a very important tool in understanding the concerns and suffering of the patient from their perspective, so that the patient feels understood and has been given assistance (12-15). There are many definitions and theories regarding this subject (16-18). Some studies $(16,19)$ suggest that empathy in physicians would lead to better patient care because (a) it increases satisfaction $(2,19)$, (b) it increases indulgency (20), (c) it enhances the ability of physicians to diagnose and treat (20), and (d) it could lead to a significant reduction in medical malpractice (21). Empathy also has significant effect on improving clinical outcomes $(9,13)$. The Jefferson Scale of Empathy (JSE) is an instrument that

\section{Corresponding author:}

Amir Akhavan Rezayat, Student Research Committee, Mashhad University of Medical Sciences, Mashhad, Iran. Tel: +98.9153114381, Email: Akhavana891@mums.ac.ir Received: June 09, 2016, Accepted: September 22, 2016, Published: December 2016

iThenticate screening: August 14, 2016, English editing: November 04, 2016, Quality control: December 02, 2016 (C) 2016 The Authors. This is an open access article under the terms of the Creative Commons Attribution-NonCommercialNoDerivs License, which permits use and distribution in any medium, provided the original work is properly cited, the use is non-commercial and no modifications or adaptations are made. 
has been designed to assess empathy in the medical profession (HP version) and related students (S-version) (22). In Iran, several studies have been carried out in the field on medical students $(2,22)$, but there is no study regarding one of the most important components of the patient-physician relationship which is among RAs and their potential as future professionals. This study has been conducted to evaluate empathy among RAs for the first time. The aim of this study was to measure empathy score among RAs in Mashhad, Iran, during a period from March to September, 2015.

\section{Material and Methods}

\subsection{Participants}

This cross sectional study was performed from March to September, 2015. Similar studies were used to determine the sample size (3). In Iran, a traditional curriculum is followed, with 4 year programs for different specialties. The Iranian student version of the JPSE-S was distributed to 120 clinical RAs from five large governmental hospitals in Mashhad (Iran) in September 2015 and they were give twenty minutes to independently complete the questionnaire. A total of 98 volunteers completed the JSPE-S. Participation was completely voluntary and RAs received no remuneration for their part in the study. The protocol was approved by Research Ethics Committee of Mashhad University of Medical Sciences. The study was performed in accordance with the Declaration of Helsinki and subsequent revisions. Written informed consents were obtained from the RAs before entering the study.

\subsection{Measures}

JSPE-Health Professional Version is an instrument to measure patient care among physicians (17). JSPE is a selfreport tool and includes 20 Likert-type items answered on a seven point scale (from strongly disagree to strongly agree). Persian translation of this scale has been used by previous studies (2). The same translation was used in this study. Furthermore, a factor structure of JSE has been evaluated using Exploratory Factor Analysis (EFA) and a three-factor structure has been used, including perspective taking, compassionate care, and ability to stand in patients' shoes (14).

\subsection{Statistical analysis}

The data of this study were analyzed using SPSS version 17 (SPSS Inc., Chicago, Illinois, USA) descriptive statistics including tests for assessing the normality of the data and independent-samples t-test to assess the difference of empathy between the two sexes. Independent sample t-test and multivariate analysis of variance (MANOVA) were used to assess the effect of gender on scores of JSE and its three factors. In order to investigate the underlying components of the JSPE, data were subjected to principal component analysis (PCA) by using Varimax rotation method.

\section{Results}

Of the 120 RAs who received the JSPE-S, 98 completed and returned the survey. Seventy Four of the 98 who completed the survey were effective, giving an overall effective response rate of $83.5 \%$. The average age was 31.49 \pm 4.49 and the majority were male (58\%). There were three specialties: $15(20.3 \%)$ in surgery, $30(40.5 \%)$ in internal medicine, and $29(39.2 \%)$ in psychiatry. There were no statistically significant differences between the groups regarding gender and age $(\mathrm{p} \geq 0.05)$. Mean score of JSE in the sample was $87.06( \pm 15.14)$. Mean score of JSE in female was $83.87( \pm 15.68)$ and in male was $89.37( \pm 14.48)$. The mean scores for each of the three factors of the scale were also calculated. The mean scores for perspective taking were $38.90( \pm 13.11)$ and compassionate care were $39.27( \pm 7.94)$, Standing in the patients' shoes was $8.89( \pm 2.80)$. Construct validity of the empathy scale showed that three meaningful factors emerged. Table 1 shows the rotated factor loadings for the JSPE, based on the responses of the 70 RAs. Subsequent tests of between-subjects effects showed that the female group scored significantly higher on perspective taking ( $\mathrm{p}=0.044$ ) (Mean of perspective taking in female vs. male: $39.7 / 35.7$ ). Also, an inverse significant relationship was found between the RAs' age and mean empathy score (Pearson correlation $=-0.204, p=0.08$ ). Statistical analysis showed that perspective taking between the two age groups was statistically significant $(\mathrm{p}=0.027$; confidence interval $\mathrm{CI}=1.39-13.35)$. Spearman's rho test also showed a significant negative correlation between age and average score of empathy (Correlation coefficient: $-0.257 ; \mathrm{p}=0.02$ ). Among the three specialties: psychiatric, internal medicine, and surgery, statistical analysis showed that there was a significant difference in total empathy score and perspective taking. Total empathy score $(p=0.001)$ and perspective taking $(\mathrm{p}=0.008)$. Post hoc tests also showed that empathy score in psychiatric RAs is more than surgery RAs (Table 2, Figure 1). In the fourth year of education, students had higher perspective taking scores than students in second year $(\mathrm{p}=0.04)$. In compassionate care between groups, there was a significant difference $(\mathrm{p} \leq 0.001)$ and the average score of empathy extended further by increasing the interest in their field. 
Table 1. Rotated Factor Loadings for the Jefferson Scale of Physician Empathy, Based on the Responses of 70 Physicians

\begin{tabular}{|c|c|c|c|c|}
\hline Question & $\begin{array}{l}\text { Factor } \\
1\end{array}$ & $\begin{array}{l}\text { Factor } \\
2\end{array}$ & $\begin{array}{l}\text { Factor } \\
3\end{array}$ & $\begin{array}{l}\text { Factor } \\
4\end{array}$ \\
\hline $\begin{array}{l}\text { 1. An important component of the relationship with my patients is my } \\
\text { understanding of the emotional status of the patients and their families. }\end{array}$ & & 0.456 & -0.397 & \\
\hline $\begin{array}{l}\text { 2. I try to understand what is going on in my patients' minds by paying } \\
\text { attention to their nonverbal cues and body language. }\end{array}$ & 0.880 & & & \\
\hline $\begin{array}{l}\text { 3. I believe that empathy is an important therapeutic factor in medical } \\
\text { treatment. }\end{array}$ & & & & -0.662 \\
\hline $\begin{array}{l}\text { 4. Empathy is a therapeutic skill without which my success as a physician } \\
\text { would be limited. }\end{array}$ & 0.585 & & & \\
\hline $\begin{array}{l}\text { 5. My understanding of my patients' feelings gives them a sense of } \\
\text { validation that is therapeutic in its own right. }\end{array}$ & & 0.445 & & \\
\hline 6. My patients feel better when I understand their feelings. & & 0.501 & & -0.411 \\
\hline $\begin{array}{l}\text { 7. I consider understanding my patients' body language as important as } \\
\text { verbal communication in physician-patient relationships. }\end{array}$ & & 0.690 & & \\
\hline $\begin{array}{l}\text { 8. I try to imagine myself in my patients' shoes when providing care to } \\
\text { them }\end{array}$ & & 0.703 & & \\
\hline $\begin{array}{l}\text { 9. I have a good sense of humor, which I think contributes to a better } \\
\text { clinical outcome. }\end{array}$ & 0.367 & & -0.591 & \\
\hline 10. I try to think like my patients in order to render better care. & 0.786 & & & \\
\hline $\begin{array}{l}\text { 11. Patients' illnesses can be cured only by medical treatment; therefore, } \\
\text { affectional ties to my patients cannot have a significant place in this } \\
\text { endeavor. }\end{array}$ & & 0.504 & & \\
\hline $\begin{array}{l}\text { 12. Attentiveness to my patients' personal experiences is irrelevant to } \\
\text { treatment effectiveness. }\end{array}$ & & 0.669 & -0.439 & \\
\hline $\begin{array}{l}\text { 13. I try not to pay attention to my patients' emotions in interviewing and } \\
\text { history taking. }\end{array}$ & 0.436 & & 0.535 & -0.371 \\
\hline 14. I believe that emotion has no place in the treatment of medical illness. & & 0.302 & -0.840 & \\
\hline $\begin{array}{l}\text { 15. I do not allow myself to be touched by intense emotional relationships } \\
\text { among my patients and their family members. }\end{array}$ & 0.674 & & & \\
\hline $\begin{array}{l}\text { 16. My understanding of how my patients and their families feel is an } \\
\text { irrelevant factor in medical treatment. }\end{array}$ & 0.717 & -0.402 & & \\
\hline 17. I do not enjoy reading nonmedical literature or experiencing the arts & & & & -0.727 \\
\hline $\begin{array}{l}\text { 18. I consider asking patients about what is happening in their lives an } \\
\text { unimportant factor in understanding their physical complaints. }\end{array}$ & & & 0.573 & 0.384 \\
\hline 19. It is difficult for me to view things from my patients' perspectives. & & & -0.563 & \\
\hline $\begin{array}{l}\text { 20. Because people are different, it is almost impossible for me to see } \\
\text { things from my patients' perspectives. }\end{array}$ & 0.702 & & & \\
\hline Eigenvalue & 4.490 & 3.261 & 1.720 & 1.611 \\
\hline$\%$ Variance & 22.450 & 16.305 & 8.599 & 8.099 \\
\hline
\end{tabular}

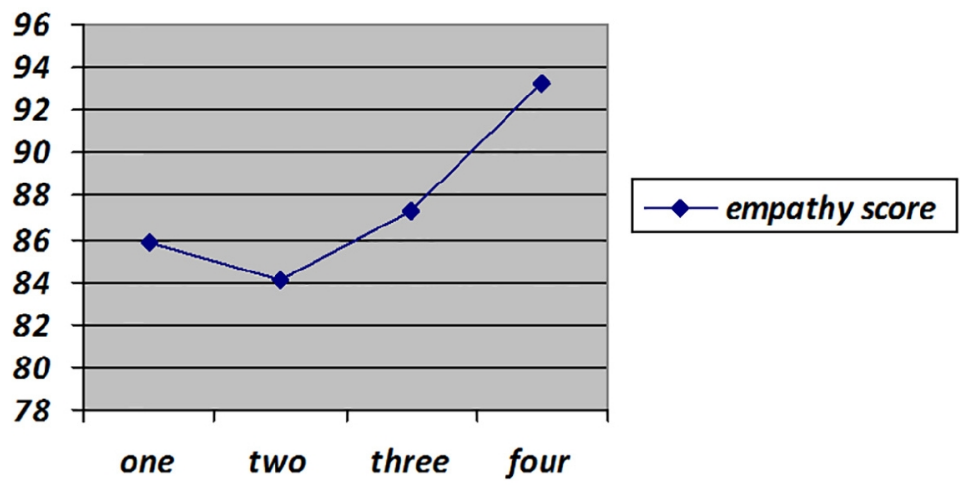

Figure 1. Empathy score among years of education 
http://www.ephysician.ir

Table 2. Empathy score among different specialties

\begin{tabular}{|l|l|l|l|l|l|}
\hline Dependent Variable & (I) Specialty & (J) Specialty & Mean Difference (I-J) & Std. Error & p-value \\
\hline Perspecting taking & \multirow{2}{*}{ Surgery } & Internal medicine & 0.10000 & 3.95688 & 1.000 \\
\cline { 3 - 6 } & & psychiatric & $-9.55862^{*}$ & 3.97956 & 0.049 \\
\cline { 2 - 6 } & Internal medicine & Surgery & -0.10000 & 3.95688 & 1.000 \\
\cline { 3 - 6 } & & psychiatric & $-9.65862^{*}$ & 3.25851 & 0.011 \\
\cline { 2 - 6 } & \multirow{2}{*}{ psychiatric } & Surgery & $9.55862^{*}$ & 3.97956 & 0.049 \\
\cline { 3 - 6 } & & Internal medicine & $9.65862^{*}$ & 3.25851 & 0.011 \\
\hline \multirow{2}{*}{ total Empathy score } & \multirow{2}{*}{ Surgery } & Internal medicine & -1.30000 & 4.40502 & 0.953 \\
\cline { 3 - 6 } & & psychiatric & $-13.79770^{*}$ & 4.43026 & 0.007 \\
\cline { 2 - 6 } & \multirow{2}{*}{ Internal medicine } & Surgery & 1.30000 & 4.40502 & 0.953 \\
\cline { 3 - 6 } & & psychiatric & $-12.49770^{*}$ & 3.62755 & 0.003 \\
\cline { 2 - 6 } & \multirow{2}{*}{ psychiatric } & Surgery & $13.79770^{*}$ & 4.43026 & 0.007 \\
\cline { 3 - 6 } & & Internal medicine & $12.49770^{*}$ & 3.62755 & 0.003 \\
\hline
\end{tabular}

\section{Discussion}

The aim of this study was to examine the levels of patient empathy in RAs. The mean empathy score of this study $($ mean $=87.67)$ was lower than in the Japanese $($ mean $=104.3)$, Kuwaiti $($ mean $=104.6)$, Iranian medical students $($ mean $=105.1$ and 110.41), and Chinese (mean $=109.60)(22-24)$ studies respectively. This may be due to the differences in cultural factors, custom, ethnicity, spiritual belief, educational system, variation of selection of RAs, and availability of appropriate role model. Average score of empathy was higher in women than in men, which is similar to other studies (25) (26-29). Also in dental students, it was shown that females scored significantly higher on the JSPE than males $(29,30)(31)$. Women show a greater understanding of the emotional support, which is important to develop interpersonal relationships with patients (32). Also, several studies have shown that female physicians (2) and female medical students $(1,23)$ gain higher empathy scores in the care of patients. The results of this study are aligned with previous studies. However, few studies have shown no gender difference in empathy (3334). Gender also has shown the difference of empathy in the three factors of the scale and observed that, difference exists only in perspective taking, while in the study of van Ryn et al. (33), in both domains of perspective taking and compassionate care, there were significant differences. In the study of Prabhu et al. (34), the mean empathy score of male students is greater than that of female students. In this study, regarding empathy among different ages, there was a decrease with increase in age, which is similar with the study of Khademalhosseini et al. (30). But in a Deliang Wen study, there were no significant differences in the age groups. These studies are similar to those of Chinese (25), Japanese (23), Korean (33), Portuguese (34), and Kuwaiti (24) medical students, but were different with American $(35,36)$ medical students. It seems that the differences in culture are partly justified. In this study, empathy score among RAs was found to increase by the advance in their educational years. RAs should be educated in a way that they learn both scientific concepts of medicine and communication with patients and also learn how to empathize with them. RAs must learn how to treat patients, not just to treat their diseases $(29,37)$. A cohort study conducted on internal residency students showed that the amount of empathy with patients was much higher in the first year as compared to the last year of specialty (38), which was contradictory to our study.

\section{Limitations}

This study was cross-sectional in nature so causal inference can not be mentioned and also a prospective study is needed to follow RAs annually from the beginning of first year until graduation, Also larger study populations covering different RAs are required to validate the results of this study

\section{Conclusions}

This study shows significant differences in total empathy score and perspective taking in three specialties. Practical significance of these findings is that there is need for a curriculum regarding Iranian student residence assistants. With an increased sample size, a cohort study could be a possible route for future research on this topic.

\section{Acknowledgments:}

The authors would like to thank Psychiatry and Behavioral Sciences Research Center, Ibn-e-Sina Hospital, Mashhad University of Medical Sciences. The voluntary participation and cooperation of the RAs in the study is highly appreciated. 


\section{Conflict of Interest:}

There is no conflict of interest to be declared.

\section{Authors' contributions:}

All authors contributed to this project and article equally. All authors read and approved the final manuscript.

\section{References:}

1) Hojat M, Vergare MJ, Maxwell K, Brainard G, Herrine SK, Isenberg GA, et al. The devil is in the third year: a longitudinal study of erosion of empathy in medical school. Acad Med. 2009; 84(9): 1182-91. doi: 10.1097/ACM.0b013e3181b17e55. PMID: 19707055.

2) Shariat SV, Habibi M. Empathy in Iranian medical students: Measurement model of the Jefferson Scale of Empathy. Med teach. 2013; 35(1): 913-8. doi: 10.3109/0142159X.2012.714881. PMID: 22938682.

3) Neumann M, Scheffer C, Tauschel D, Lutz G, Wirtz M, Edelhäuser F. Physician empathy: definition, outcome-relevance and its measurement in patient care and medical education. GMS Z Med Ausbild. 2012; 29(1): Doc11. doi: 10.3205/zma000781. PMID: 22403596, PMCID: PMC3296095.

4) Dixon DM, Sweeney KG, Gray DJ. The physician healer: ancient magic or modern science? Br J Gen Pract. 1999; 49(441): 309-12. PMID: 10736913, PMCID: PMC1313401.

5) Usherwood T. Understanding the consultation: evidence, theory and practice. McGraw-Hill International. 1999.

6) Lewis JR. Patient views on quality care in general practice: literature review. Soc Sci Med. 1994; 39(5): 655-70. doi: 10.1016/0277-9536(94)90022-1. PMID: 7973865.

7) Mercer SW, Reynolds WJ. Empathy and quality of care. Br J Gen Pract. 2002; 52(Suppl): 9-12. PMID: 12389763, PMCID: PMC1316134.

8) Mercer SW, Maxwell M, Heaney D, Watt GC. The consultation and relational empathy (CARE) measure: development and preliminary validation and reliability of an empathy-based consultation process measure. Family practice. 2004; 21(6): 699-705. doi: 10.1093/fampra/cmh621. PMID: 15528286.

9) Hojat M, Gonnella JS, Mangione S, Nasca TJ, Veloski JJ, Erdmann JB, et al. Empathy in medical students as related to academic performance, clinical competence and gender. Med Educ. 2002; 36(6): 522-7. doi: 10.1046/j.1365-2923.2002.01234.x. PMID: 12047665.

10) Spiro H, Curnen M, Peschel E, James DS. Empathy and the practice of medicine: beyond pills and the scalpel: Yale University Press. 1996; 16(5).

11) Jha V, Bekker HL, Duffy SR, Roberts TE. A systematic review of studies assessing and facilitating attitudes towards professionalism in medicine. Med Educ. 2007; 41(8): 822-9. doi: 10.1111/j.13652923.2007.02804.x. PMID: 17661891.

12) Hojat M, Louis DZ, Markham FW, Wender R, Rabinowitz C, Gonnella JS. Physicians' empathy and clinical outcomes for diabetic patients. Acad Med. 2011; 86(3): 359-64. doi: 10.1097/ACM.0b013e3182086fe1. PMID: 21248604.

13) Del Canale S, Louis DZ, Maio V, Wang X, Rossi G, Hojat M, et al. The relationship between physician empathy and disease complications: an empirical study of primary care physicians and their diabetic patients in Parma, Italy. Acad Med. 2012; 87(9): 1243-9. doi: 10.1097/ACM.0b013e3182628fbf. PMID: 22836852.

14) Hojat M. Empathy in patient care: Antecedents, development, measurement, and outcomes. Springer Science \& Business Media. 2007.

15) Hojat M, Vergare M, Isenberg G, Cohen M, Spandorfer J. Underlying construct of empathy, optimism, and burnout in medical students. Int $\mathrm{J}$ Med Educ. 2015; 6: 12-6. doi: 10.5116/ijme.54c3.60cd. PMID: 25633650, PMCID: PMC4332366.

16) Díaz Narváez VP, Alonso Palacio LM, Caro SE, Silva MG, Castillo JA, Bilbao JL, et al. Empathic orientation among medical students from three universities in Barranquilla, Colombia and one university in the Dominican Republic. Arch Argent Pediatr. 2014; 112(1): 41-9. doi: 10.1590/S032500752014000100008. PMID: 24566781.

17) Hojat M, Gonnella JS, Nasca TJ, Mangione S, Veloksi JJ, Magee M. The Jefferson Scale of Physician Empathy: further psychometric data and differences by gender and specialty at item level. Acad Med. 2002; 77(10): 58-60. PMID: 12377706.

18) Fernández Pinto I, López Pérez B, Márquez M. Empatía: Medidas, teorías y aplicaciones en revisión. 2008; 24(2): 284-98. 
19) Beckman HB, Frankel RM. The effect of physician behavior on the collection of data. Ann Intern Med. 1984; 101(5): 692-6. PMID: 6486600.

20) Falvo D, Tippy P. Communicating information to patients: patient satisfaction and adherence as associated with resident skill. J Fam Pract. 1988; 26(6): 643-7. PMID: 3379367.

21) Levinson W, Roter DL, Mullooly JP, Dull VT, Frankel RM. Physician-patient communication: the relationship with malpractice claims among primary care physicians and surgeons. Jama. 1997; 277(7): 553-9. PMID: 9032162.

22) Rahimi-Madiseh M, Tavakol M, Dennick R, Nasiri J. Empathy in Iranian medical students: a preliminary psychometric analysis and differences by gender and year of medical school. Med Teach. 2010; 32(11): 471-8. doi: 10.3109/0142159X.2010.509419. PMID: 21039088.

23) Kataoka HU, Koide N, Ochi K, Hojat M, Gonnella JS. Measurement of empathy among Japanese medical students: psychometrics and score differences by gender and level of medical education. Acad Med. 2009; 84(9): 1192-7. doi: 10.1097/ACM.0b013e3181b180d4. PMID: 19707056.

24) Morling B, Lamoreaux M. Measuring culture outside the head: A meta-analysis of individualismcollectivism in cultural products. Pers Soc Psychol Rev. 2008; 12(3): 199-221. doi: 10.1177/1088868308318260. PMID: 18544712.

25) Wen D, Ma X, Li H, Liu Z, Xian B, Liu Y. Empathy in Chinese medical students: psychometric characteristics and differences by gender and year of medical education. BMC medical education. 2013; 13(1): 130. doi: 10.1186/1472-6920-13-130.

26) Hojat M, Gonnella JS, Nasca TJ, Mangione S, Vergare M, Magee M. Physician empathy: definition, components, measurement, and relationship to gender and specialty. Am J Psychiatry. 2002; 159(9): 15639. doi: 10.1176/appi.ajp.159.9.1563. PMID: 12202278.

27) Preusche I, Lamm C. Reflections on empathy in medical education: What can we learn from social neurosciences? Adv Health Sci Educ Theory Pract. 2016; 21(1): 235-49. doi: 10.1007/s10459-015-9581-5. PMID: 25597025.

28) Paro HB, Silveira PS, Perotta B, Gannam S, Enns SC, Giaxa RR, et al. Empathy among medical students: is there a relation with quality of life and burnout? PloS one. 2014; 9(4): 94133. doi: 10.1371/journal.pone.0094133. PMID: 24705887, PMCID: PMC3976378.

29) Khademalhosseini M, Khademalhosseini Z, Mahmoodian F. Comparison of empathy score among medical students in both basic and clinical levels. J Adv Med Educ Prof. 2014; 2(2): 88-91. PMID: 25512926, PMCID: PMC4235551.

30) Sherman JJ, Cramer A. Measurement of changes in empathy during dental school. J Dent Educ. 2005; 69(3): 338-45. PMID: 15749944.

31) Vallabh K. Psychometrics of the student version of the Jefferson Scale of Physician Empathy (JSPE-S) in final-year medical students in Johannesburg in 2008. South African Journal of Bioethics and Law. 2011; 4(2): 63-8.

32) Mostafa A, Hoque R, Mostafa M, Rana MM, Mostafa F. Empathy in Undergraduate Medical Students of Bangladesh: Psychometric Analysis and Differences by Gender, Academic Year, and Specialty Preferences. ISRN psychiatry. 2014; 2014: 7. doi: 10.1155/2014/375439.

33) Roh MS, Hahm BJ, Lee DH, Suh DH. Evaluation of empathy among Korean medical students: a crosssectional study using the Korean Version of the Jefferson Scale of Physician Empathy. Teach Learn Med. 2010; 22(3): 167-71. doi: 10.1080/10401334.2010.488191. PMID: 20563934.

34) Magalhães E, Salgueira AP, Costa P, Costa MJ. Empathy in senior year and first year medical students: a cross-sectional study. BMC Med Educ. 2011; 11(1): 52. doi: 10.1186/1472-6920-11-52. PMID: 21801365, PMCID: PMC3163625.

35) Hojat M, Mangione S, Nasca TJ, Rattner S, Erdmann JB, Gonnella JS, et al. An empirical study of decline in empathy in medical school. Med Educ. 2004; 38(9): 934-41. doi: 10.1111/j.1365-2929.2004.01911.x. PMID: 15327674.

36) Chen D, Lew R, Hershman W, Orlander J. A cross-sectional measurement of medical student empathy. J Gen Intern Med. 2007; 22(10): 1434-8. doi: 10.1007/s11606-007-0298-x. PMID: 17653807, PMCID: PMC2305857.

37) Allen D, Wainwright M, Mount B, Hutchinson T. The wounding path to becoming healers: medical students' apprenticeship experiences. Med teach. 2008; 30(3): 260-4. doi: 10.1080/01421590701758665. PMID: 18484452.

38) Bellini LM, Shea JA. Mood change and empathy decline persist during three years of internal medicine training. Acad Med. 2005; 80(2): 164-7. doi: 10.1097/00001888-200502000-00013. PMID: 15671323. 